\title{
A COMPLETE MORPHOLOGICAL STUDY OF THE RIGHT HAND OF BRONZO “A” DI RIACE
}

\author{
M. Muzzupappa, A. Gallo, *, R. M. Mattanò, C. Ruggiero, F. Bruno
}

Departrment of Mechanical Engineering, University of Calabria, 87036 Rende (CS), Italy - muzzupappa@unical.it, alessandro.gallo@unical.it,r.mattano@unical.it, carm.ruggiero@gmail.com,f.bruno@unical.it

KEY WORDS: Reverse Engineering, Riace Bronzes

\begin{abstract}
:
The Riace Bronzes represent one of the most important masterpieces of Magna Graecia archaeology, and of the whole world artistic heritage. The Bronzes, other than for their exquisite workmanship, are also interesting for the mysteries which surround their history. The countless hypotheses about their identity, origin and authors are supported by many studies of historical and iconographic nature. This paper describes a complete morphological study of the Riace Bronzes in order to provide to the archaeologists some objective data about the shape of the most interesting and controversial part of the Bronzes: the right hand of Bronzo "A". This study aims to provide a series of geometrical data which could help to identify the object that the A Bronze was gripping. This questions is, in fact, one of the fundamental steps for the individuation of the Bronze A's identity.
\end{abstract}

\section{INTRODUCTION}

In literature there are several examples of digitization of twodimensional paintings and 3D objects of different materials, including wood, stone, marble, pottery and metals (Marc, 2000, Bernardini, 2002, Beraldin, 1999, Schindler, 2003). In the field of $3 \mathrm{D}$ scanning for cultural heritage there is a vast literature reporting studies and analyses based on different techniques and applied to different kinds of finds. Several papers are focused on the reconstruction of artefacts starting from a set of fragments. Some researchers approach the problem by searching for the best matching between the edge boundaries of the single fragments, while others adopt specific approaches to deal the problem more efficiently (Leitão, 2000, Üçoluk, 1999, Papaioannou, 2003, Kampel, 2003, Willis, 2003, Halír, 1999, De Napoli, 2002).

Virtual reconstruction has also been applied in the archaeological field to recreate the look of historic figures (Wilkinson, 2003) and mummies (Cesarani, 2004, Gill-Robinson, 2006). Combination of non-invasive technologies like 3D laser and tomographic scanners is used in paleoanthropology for 3D reconstruction of craniums (Zollikofer, 2005), of broken bones and missing fragments (Ruff, 2007a). Recently, some experiments in estimating and predicting the height and the body mass of an adult individual starting from juvenile bone fragments have been conducted (Ruff, 2007b). In (Grün, 2004), the authors describe the reconstruction of the Great Buddha, which can constitute the basis for a physical reconstruction of the colossal statues demolished by the Taliban government militia.

In the work of (Granero, 2009), a structured light scanner has been used to reconstruct a fragment of a bronze sculpture to perform an anthropomorphic study of the hand and arm giving as a result their position respect to the whole statue. In (Dellepiane, 2007) a laser scanner in conjunction to image-to-3D-model mapping techniques, has been used to evaluate the plausibility of an attribution hypothesis of a Renaissance artefact, a small bronze horse, which was discovered to be very similar to a silverpoint drawing by Leonardo.
This paper describes the reconstruction procedure and the analyses performed on the 3D model of the right hand of one of the two Riace Bronzes, housed by the Museo Nazionale della Magna Grecia in Reggio Calabria (Italy).

Riace Bronzes (Figure 1) are statues of incomparable workmanship and highly refined taste; that can be historically set in the early classical age. However it is not yet certain who was the author (or the authors) of these masterpieces. Is the author one of the famous Greek artists, Phidias, Polykleitus or Myron? Or is he an anonymous sculptor working in Magna Graecia? He was certainly a highly skilled craftsman and a sensitive artist, who almost surely lived in the 5th century BC. On the other hand, it remains a mystery also whom the two statues represent. They may be Castor and Pollux or they may depict Harmodios and Aristogeiton; or, more simply, they portray two warriors, armed of a spear and a shield, hoplites with a bold look, a proud expression and a Greek profile.
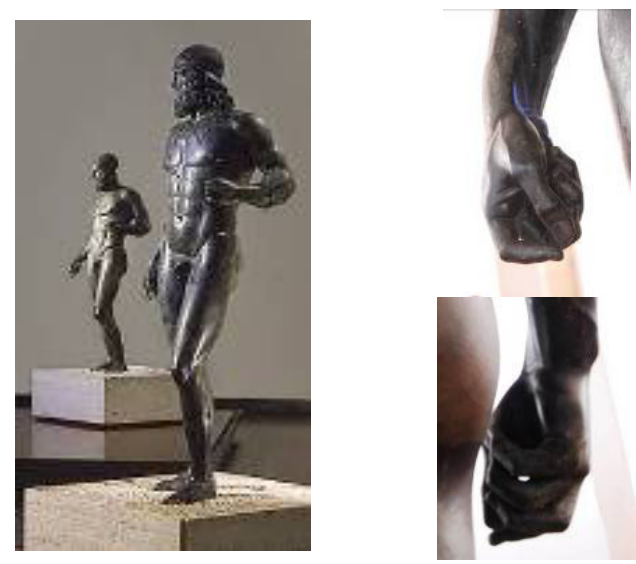

Figure 1: Riace Bronzes.

\footnotetext{
* Corresponding author.
} 
This paper, after drawing a brief historical frame, describes the acquisition procedure, carried out by $3 \mathrm{D}$ scanner, and the subsequent 3-dimensional reconstruction. The model thus obtained has been used to define quantitatively the shape and the size of the cavity within the right hand of the "A" Bronze, also termed the young. The gathered information can give useful indications on the typology of the object grasped by the statue and lost since long.

\section{WHO ARE THE RIACE BRONZES?}

According to Moreno (Moreno, 1998), the "A" bronze, the young, might represent Tydeus, a hero of greek mythology, the son of Oineus, king of Calydon, and of his daughter Gorge (or perhaps of his second wife Periboea). The trace followed by Moreno is a "baedeker", describing towns and monuments of ancient Greece, written by Pausania in the second century AD. Pausania reported that in the Polis of Argo there was a monument dedicated to the "Seven against Thebes". The monumental group was composed of about fifteen statues, carrying shields, swords, spears and elms; they, according to Moreno, included the Riace Bronzes. Stucchi (Stucchi, 1998) hypothesizes that the "A" Bronze could depict Euthymos from Locri, represented as the winner of Temesa. Stucchi believes that the statue is the work of the great sculptor Pythagoras from Rhegion. According to Paribeni (Paribeni, 1994), the "A" Bronze might portrait a hero, perhaps Ajax the Lesser, son of Oileus, and he claims the author be a Peloponnesian artist. Paribeni draws these conclusions from the craftsmanship of the "A" Bronze, which is , in his opinion, clearly non Attic. The researcher agrees with the theory that there is a noticeable chronological distance between the " $\mathrm{A}$ " and the "B" Bronze, believing the " $\mathrm{A}$ " Bronze to be a work pertaining to the severe style and the "B" one to the later classical style of the last part of the century. According to recent studies (Roma, 2009), the bronzes could depict Castor and Pollux; the statues weren't on the seabed as a consequence of a shipwreck, but they were buried intentionally. Every year, in the second Sunday of May, the population of Riace walks in procession to the cliff where the statues have been found: the relics of Saints Cosmas and Damian, the patron saints of the town, are immersed in water. Giuseppe Roma claims that this tradition is a typical example of continuity between paganism and Christianity. He mentions also that, as demonstrated by Stanley, some centuries ago the shoreline could have been some 400-500 meters wider of the current one. If one considers also that no traces of a ship have ever been found in the area where the Bronzes have been discovered, one could assume that the statues were buried in ancient times.

\section{WHAT WAS THE "A" BRONZE HOLDING IN HIS RIGHT HAND?}

The simple visual analysis of the statues allows only some general observations. The most common assumption is that each of the two statues lost three objects: an elm, a shield, a spear. On the basis of this assumption, Figure 2 shows two quite similar possible representations of the " $\mathrm{A}$ " Bronze incorporating the three missing elements. Where the object hold by the " $A$ " Bronze in his right hand is concerned, four regions can be evidenced where the hand shape differs significantly from the anatomic shape; these "excavated" zones can be considered particularly relevant with reference to the object possibly clutched. The four areas are located in the proximity of the abductor pollicis brevis muscle, of the little finger, the ring finger and the middle finger (Figure 3).
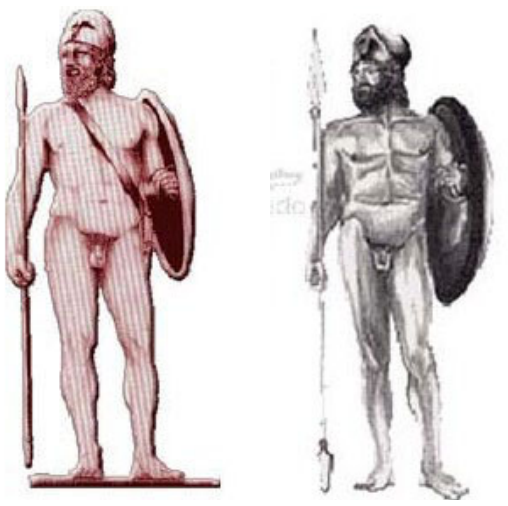

Figure 2: Reconstruction of the missing parts of the "A" Bronze.
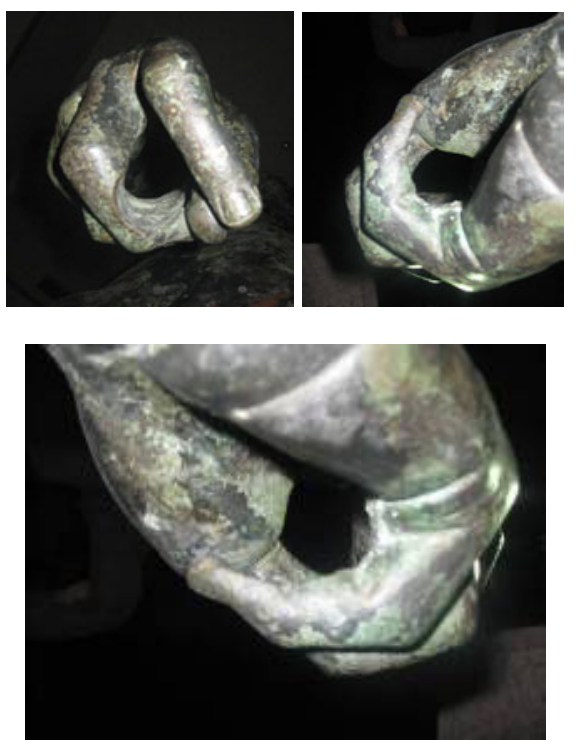

Figure 3: Details of the hand of the " $A$ " Bronze.

The " $A$ " Bronze seizes the missing object in a particular way. With the right hand stretched out, on his back on the horizontal plane, he flexes his fingers, adducts the index finger and inserts the missing element between the index and the middle finger, while the other fingers grip and wrap the object.

This way of gripping an object, if it could be unusual nowadays, seems instead to be quite common in Roman and Greek paintings and sculptures. Many of these representations, in fact, show warriors or famous persons in the act of holding lances, scepters or staffs with this particular modality (Figure 4).

All the hypotheses present in literature are supported by iconographic studies and/or historical sources. This research wants instead to provide to the scholars a series of objective confirmations on geometrical data, which are not easily measurable on the statues in a direct way. So we want to make $3 \mathrm{D}$ scanning techniques and geometrical analysis available for reconstructing and analyzing the most interesting anatomical parts, which could provide objective data for the study about the identity of the depicted characters. 

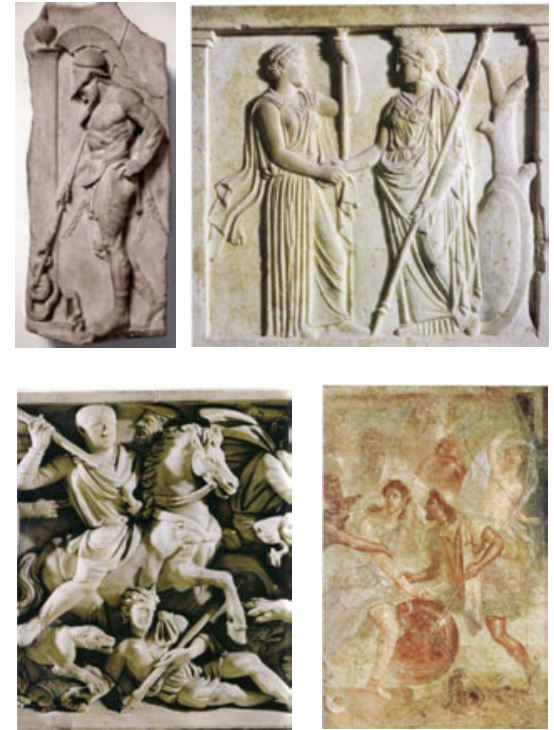

Figure 4: Paintings with various handles of spears.

The first analysis that has been carried out has concerned the shape of the Bronze A's right hand, as this presents some tissue deformations which could represent a good starting point for the analysis the hand posture and the elaboration of hypotheses about the objects which could have been gripped.

\section{THE METHODOLOGY FOR THE RECONSTRUCTION}

In order to acquire the Bronze's hand, we have used a structured light scanner, that are also well-renowned and widespread in 3D reverse engineering. Special structured light beams, that produce straight horizontal and vertical lines, are projected on the object. Following the principle of photogrammetry, two images taken by two different cameras are interpolated and the result is a dense point cloud. The scanner used in this process was a laser structured light scanner produced by Scansystems S.r.l.

The main obstacle which we met in this study is related to the fact that the hand, being closed as to grip something and placed near the hip, presents some hardly accessible areas. This happens because the scanner needs to observe a point simultaneously with both cameras in order to acquire it. The hand has been acquired from various positions, in order to achieve a full shape of the object that can include also the internal part of hand (Figure 5). With the use of multiple scanning positions we were able to cover around $95 \%$ of the hand limiting the missing parts reconstructed by interpolation - to only a $5 \%$ : This allows us to affirm that the fidelity of the reconstructed model is adequate to carry out quantitative analyses on it. In total, we carried out 25 scanning processes, obtaining 2.473 .171 points.

The subsequent triangulation between the points and the effective division in polygons is executed by 3D modelling software tools. The proprietary Scanprobe software has been used for $3 \mathrm{D}$ acquisition and patches registration. The same software has been employed for noise reduction and triangulation. Fine retouches and missing parts reconstruction have been done with Meshlab. After this phase, the final number of points was 191.952. Finally, using a 3D painting software, the CAD model was finished with the texture (Figure 6).
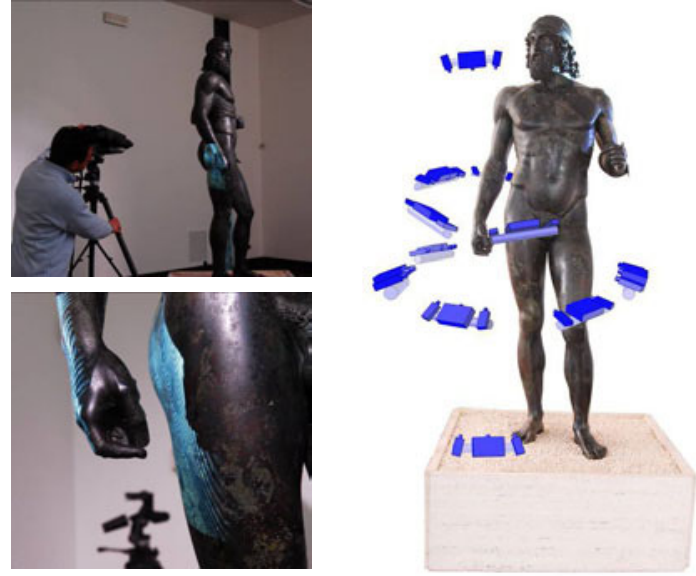

Figure 5: The acquisition procedure.
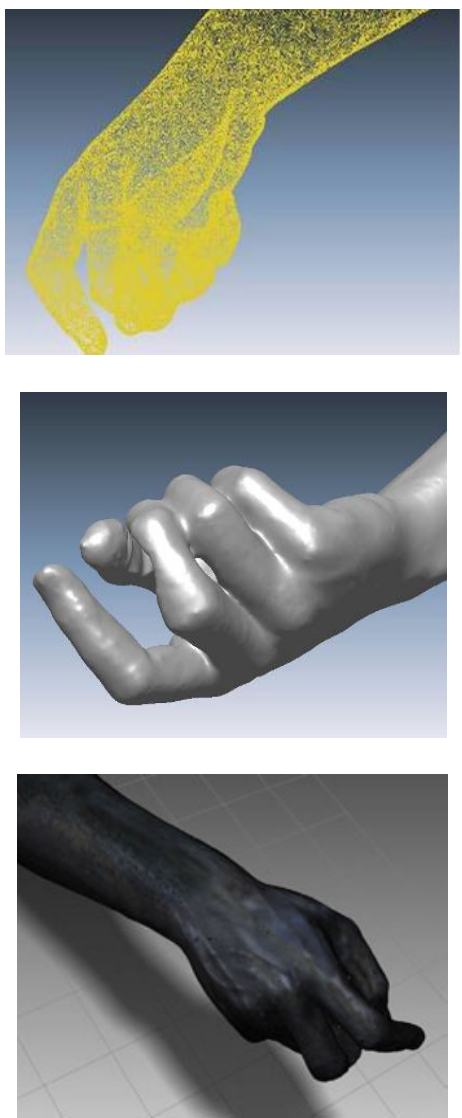

Figure 6: Cloud of points, polygonal and textured model of the right hand.

\section{MODEL ANALYSIS}

Once obtained the virtual model of the hand, we were able to carry out a series of analysis, aiming to determine shape and dimensions of the internal cavity of the right hand of the A Bronze. First of all, showing the 3D model of the hand to archaeologists, they were able to appreciate the possibility of a free rotation of the object, allowing them to observe the object from angles that, due to the proximity of the hand with the body, would have been impossible to visualize. In particular, the hand 
is contained in a $182 \times 101 \times 105 \mathrm{~mm}$ box. The first analysis concerned a part of the middle finger which presents an evident flattening: its profile looks like a circular arc. In proximity of this flattening we defined the maximum inscribable cylinder, and on the base of its axis we realized 14 sections, spaced of $10 \mathrm{~mm}$. This subdivision has allowed to determine the maximum inscribed circumferences in each section, as well as the internal volume (Figure 7).
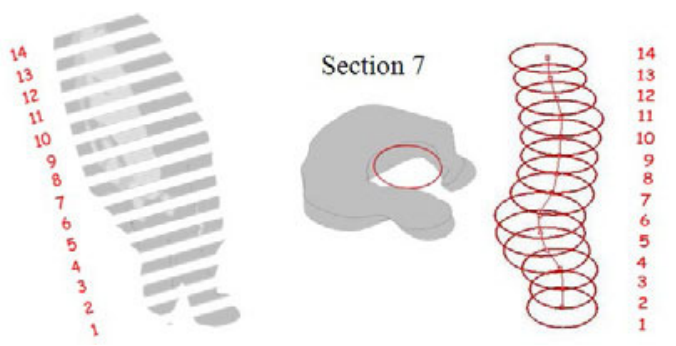

Figure 7: Subdivision of the hand in 14 sections

In table 1 , the 14 diameters related to the circumferences obtained in every section are shown.

\begin{tabular}{|l|c|c|c|c|c|}
\hline Sections & $\mathbf{1}$ & $\mathbf{2}$ & $\mathbf{3}$ & $\mathbf{4}$ & $\mathbf{5}$ \\
\hline $\begin{array}{l}\text { Diameter } \\
\text { max (mm) }\end{array}$ & 33.8 & 31.6 & 36.1 & 41.1 & 41.6 \\
\hline Sections & $\mathbf{6}$ & $\mathbf{7}$ & $\mathbf{8}$ & $\mathbf{9}$ & $\mathbf{1 0}$ \\
\hline $\begin{array}{l}\text { Diameter } \\
\text { max (mm) }\end{array}$ & 42.8 & 38.3 & 37.1 & 34.6 & 36.1 \\
\hline Sections & $\mathbf{1 1}$ & $\mathbf{1 2}$ & $\mathbf{1 3}$ & $\mathbf{1 4}$ & \\
\hline $\begin{array}{l}\text { Diameter } \\
\text { max (mm) }\end{array}$ & 37.9 & 35.3 & 32.3 & 32.8 & \\
\hline
\end{tabular}

Table 1. Diameters of circles inscribed into the hand.

In relation to the 4 hand sections, in which the palm deformation deviates from the anatomical configuration, i.e. an evident tissue flattening is present, the corresponding diameters are, respectively:

1) $33,8 \mathrm{~mm}$ - section corresponding to the middle finger (section $\left.\mathrm{n}^{\circ} 1\right)$.

2) $38,3 \mathrm{~mm}$ - section corresponding to the ring finger (section $\left.\mathrm{n}^{\circ} 7\right)$;

3) $36,1 \mathrm{~mm}$ - section corresponding to the little finger (section $\left.\mathrm{n}^{\circ} 10\right)$;

4) $32,3 \mathrm{~mm}$ - section corresponding to the abductor pollicis brevis $\left(\right.$ section $\left.\mathrm{n}^{\circ} 13\right)$.

Assuming the hypothesis of the presence of a spear in the right hand of the A Bronze, it is possible to state that there is a cylindrical element, with an about $30 \mathrm{~mm}$ maximum diameter, which is always contained inside the volume defined by the 14 circumferences. This element is adjacent to the points of the hand corresponding to the deformations that deviate from the natural anatomical configuration (circles 1-7-10-13 of Figure 8). Figure 9 shows these sections, the maximum inscribed circumferences and the relative position of the cylinder.

Obviously, it is always possible to hypothesize the presence of an object, with a non-rectilinear axis or with a non-cylindrical shape, contained inside the volume of the palm of the hand. Figure 10 shows two possible reconstructions. In Figure 10-a, the most likely reconstruction of a spear, $2 \mathrm{~m}$ long with a $30 \mathrm{~mm}$ diameter, is shown; Figure 10-b shows an unlikely solution (Roma, 2009): the bronze holding the rein of a horse.
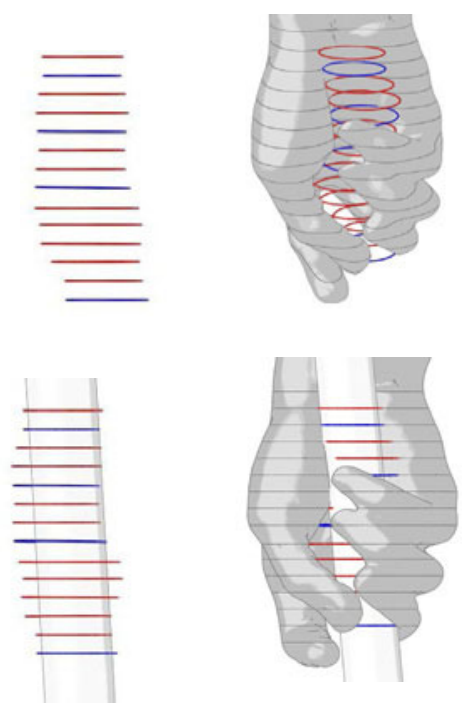

Figure 8: Maximum inscribed cylinder contained inside the volume defined by the 14 circumferences and adjacent to sections 1-7-10-13.

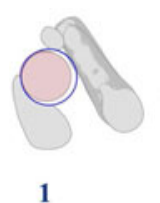

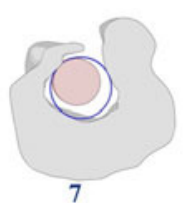

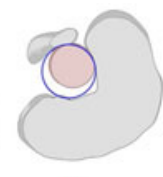

10

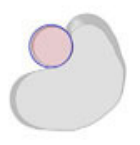

13
Figure 9: Details of the sections 1-7-10-13 with the inscribed cylinder of $30 \mathrm{~mm}$ of diameter.

\section{CONCLUSIONS}

In this paper, we have described the reconstruction procedure and the analyses performed on the 3D model of the right hand of one of the two Riace Bronzes, housed by the Museo Nazionale della Magna Grecia in Reggio Calabria (Italy). In particular, this study has provided a series of geometrical data useful to identify the object that the A Bronze was gripping. Without entering into merits about the individuation of the Bronze A's identity, we can assume which is very likely that the Bronze held a spear of $30 \mathrm{~mm}$ and a length of about $2200 \mathrm{~mm}$.

This experience has confirmed that the morphological study using virtual 3D models can be considered an effective tool to validate both formal and historical/scientific assumptions.

Although this work did not bring immediate profits at the Museo Nazionale della Magna Grecia in Reggio Calabria, the data collected (in VRML format) constitute an efficient repository and an useful database for future study or for any restoration work.

\section{REFERENCES}

\section{References from Journals:}

Bernardini, F., Rushmeier, H., Martin, I.M., Mittleman, J., Taubin, G., 2002. Building a digital model of Michelangelo's Florentine Pieta. IEEE Computer Graphics Application, 22 (1), pp. 59-67 
a)

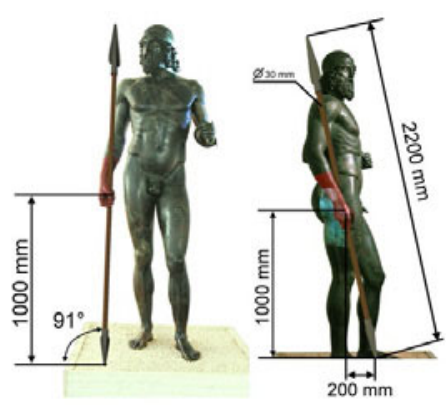

b)

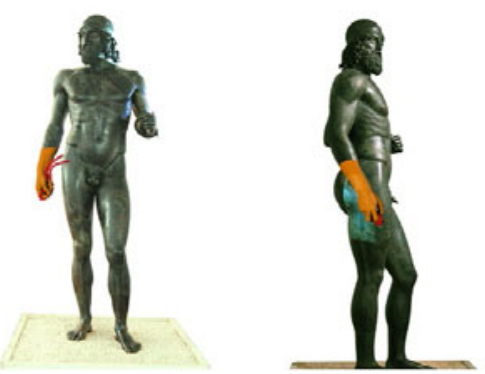

Figure 10: The two different hypothesis: (a) a spear; (b) a rein of a horse.

Cesarani, F., Martina, M.C., Grilletto, R., Boano, R., Donadoni Roveri, A.M., Capussotto, V., Giuliano, A., Celia, M., Gandini, G., 2004. Facial reconstruction of a wrapped Egyptian mummy using MDCT. Am. J. Roentgenology 183, 755-758

Gill-Robinson, H., Elias, J., Bender, F., Allard, T.T., Hoppa, D.R., 2006. Using image analysis software to create a physical skull model for the facial reconstruction of a wrapped Akhmimic mummy. J. Comput. Inf. Technol 14, 45-51.

Grün, A., Remondino F., Zhang L., 2004. Photogrammetric Reconstruction of the Great Buddha of Bamiyan, Afghanistan Authors. The Photogrammetric Record (19)-107.

Kampel M., Sablatnig R., 2003. An automated pottery archival and reconstruction system. J. Visual. Comput. Animat. 14, pp. 111-120.

Papaioannou G., Karabassi E.-A.,2003. On the automatic assemblage of arbitrary broken solid artifacts. Image and Vision Computing, 21, pp. 401-412.

Ruff, C., 2007a. Body Size Prediction from Juvenile Skeletal Remains. Am. J. Of Physical Anthropology 133:698-716.

Üçoluk G., Toroslu I. H., 1999. Automatic reconstruction of broken 3-D surface objects. Computers \& Graphics, 23, pp. 573582 .

Wilkinson, C., Neave, R., 2003. The reconstruction of a face showing a healed wound. J. Archaeol. Sci. 30, 1343-1348.

Zollikofer, C. P. E., Ponce De Leon, M S., Lieberman, D. E., Guy, F., Pilbeam, D., Likius, A., Mackaye, H. T., Vignaud, P., Brunet, M., 2005. Virtual cranial reconstruction of Sahelanthropus tchadensis, Nature, Vol 434, 7 April 2005
References from Proceedings and Books:

Beraldin, J.A., Blais, F., Cournoyer, L., Rioux, M., El-Hakim, S.H., Rodella, R., Bernier, F., Harrison, N., 1999. Digital 3D imaging system for rapid response on remote sites. In Proc. of 3DIM 1999, p. 34-42.

De Napoli L., Luchi M. L., Muzzupappa M., Rizzuti S., 2002. Recognition and Classification of Fragments from Ceramic Artefacts. In Proc. of CAA 2002, Heraklion, Crete, Greece, April 2-6.

Dellepiane, M., Callieri, M., Fondersmith, M., Cignoni, P. and Scopigno, R., 2007. Using 3D scanning to analyze a proposal for the attribution of a bronze horse to Leonardo da Vinci, in Proceedings of The 8th International Symposium on Virtual Reality, Archaeology and Cultural Heritage VAST (2007).

Granero, L., Díaz, F., Domínguez, R., Hervás, J., Simon, S., Perez, E., Olcina, M., 2009. Documentation of the roman bronze hand found in the site of "El Tossal" in Lucentum in Proceedings of 3D-ARCH 2009, 25-28 February 2009, Trento, Italy, Volume XXXVIII-5/W1.

Halír R., 1999."An automatic estimation of the axis of rotation of fragments of archaeological pottery: a multi-step model-based approach", In Proc. of WSCG99, volume 2 pp. 381-387.

Leitão H. C. G., Stolfi J.,2000. A multi-scale method for the reassembly of fragmented objects. In Proc. British Machine Vision Conference, vol. 2, 705-714.

Marc, L., Rusinkiewicz., S., Ginzton, M., Ginsberg, J., Pulli, K., Koller, D., Anderson, S., Shade, J., Curless , B., Pereira, L., Davis , J., Fulk, D., 2000. The digital Michelangelo project: 3D scanning of large statues. In Proc. of ACM SIGGRAPH, AddisonWesley, pp. 131-144.

Moreno P., 1998. I Bronzi di Riace. Il Maestro di Olimpia e i Sette a Tebe, Milano.

Paribeni G., 1994. I bronzi di Riace, in Due Bronzi.

Ruff, C., 2007b. 3D Reconstruction of Highly Fragmented Bone Fractures. In Proc. of the SPIE, Volume 6512, pp 65121P

Schindler, K., Grabner, M., Leberl, F., 2003. Fast on-site reconstruction and visualization of archaeological finds. In Proc. of CIPA Symposium, Antalya, Turkey.

\section{References from Other Literature:}

Roma G., 2009. I Bronzi di Riace: Brevi considerazioni, in “Ostraka", Anno XVI, n. 2, pp. $391-400$.

Stucchi S., 1998. Nuove osservazioni sulle statue bronzee di Riace, in Atti dell'Accademia Nazionale dei Lincei, Rendiconti XLIII.

Willis A., Orriols X., B. Cooper D. B., 2003. Accurately Estimating Sherd 3D Surface Geometry with Application to Pot Reconstruction. VPR Workshop Madison, Wisconsin. 
